\title{
Extensive Digital Contractures Caused by Gout
}

\author{
Seung Yun LEE ${ }^{1}$, Won PARK ${ }^{1}$, Seong Ryul KWON ${ }^{1} \mathbb{D}$, Yeo Ju KIM² ${ }^{2}$, \\ Mie Jin LIM $^{1}\left(\mathbb{D}\right.$, Minjae JO'D, Kyong-Hee JUNG ${ }^{1}(\mathbb{D}$ \\ ${ }^{1}$ Department of Internal Medicine, Division of Rheumatology, Inha University, Incheon, South Korea \\ ${ }^{2}$ Department of Radiology, Inha University, Incheon, South Korea
}

Gout is a very common inflammatory arthritis by monosodium urate crystal deposition with increasing incidence. ${ }^{1,2}$ Tophi appears, on average, 11.6 years after the initial acute attack of gouty arthritis. ${ }^{3}$ Most patients with digital contractures caused by tophi or tenosynovitis have undergone surgery. ${ }^{3-7}$ In this article, we report a case of successful medical treatment of extensive gouty digital flexion contractures.

A 51-year old male patient presented with an 18-month history of an inability to flex his right second to fourth fingers. There was no family history of gout. Physical examination
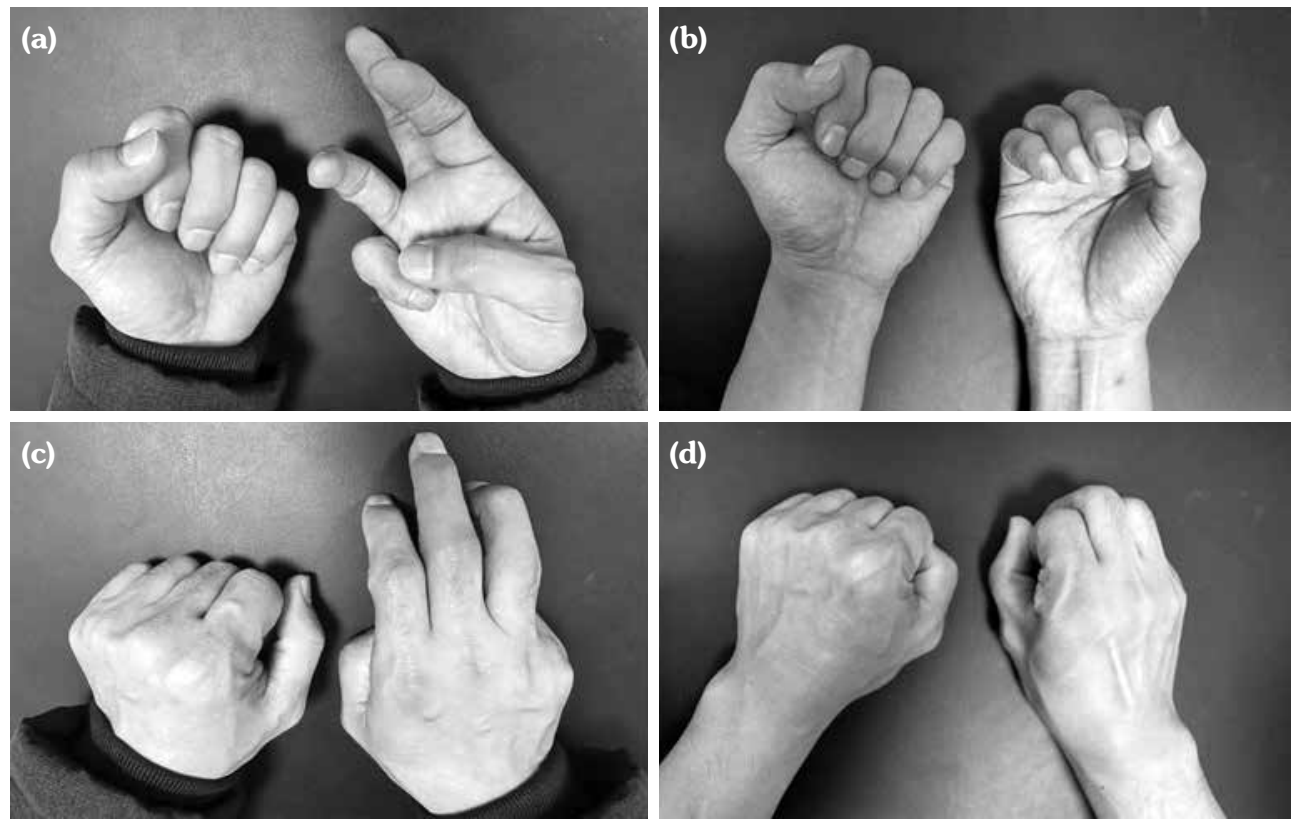

Figure 1. Active range of motion with flexion $(\mathbf{a}, \mathbf{c})$ on first visit date, and $(\mathbf{b}, \mathbf{d})$ eight months later.

Received: March 20, 2018 Accepted: March 22, 2018 Published online: April 30, 2018

Correspondence: Kyong-Hee Jung, MD. Department of Internal Medicine, Division of Rheumatology, Inha University, 22332 Incheon, South Korea. Tel: +82-32-890-2211 e-mail: khjung@inha.ac.kr

\section{Citation:}

Lee SY, Park W, Kwon SR, Kim YJ, Lim MJ, Jo M. Extensive digital contractures caused by gout. Arch Rheumatol 2019;34(1):119-121. 

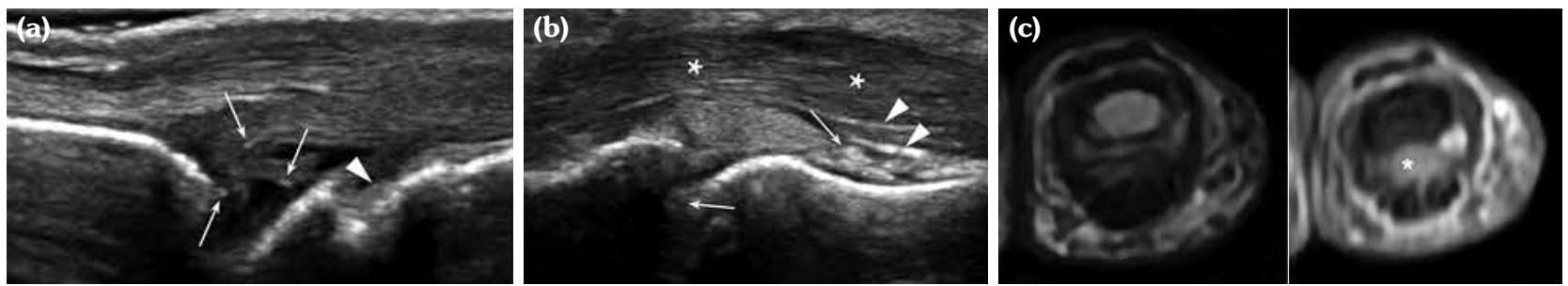

Figure 2. Ultrasonography shows (a) some tiny hyperechogenic spots (arrows), and bony erosion (arrow head) at dorsal aspect of third metacarpophalangeal joint, and (b) hyperechogenicity (arrow heads) along synovium and flexor tendon sheath suggesting monosodium urate deposition, some hyperechogenic regions (arrows), and diffuse thickening (asterisks) at flexor digitorum of second proximal interphalangeal joint. (c) Hand magnetic resonance imaging. Axial $\mathrm{T}_{2}$ weighted image (left), and gadolinium enhanced fat suppressed $T_{1}$ weighted image (right) of second fingers reveal heterogeneous signal intensities with enhancement (asterisk).

showed no mass or erythema in his hands, and no sensory deficits. Passive limitations of motion were present. The active range of motion (ROM) of the right second to fourth metacarpophalangeal (MCP) joints and that of the right second to fourth proximal interphalangeal (PIP) joints were limited to less than $5^{\circ}$ and $30^{\circ}$ of flexion, respectively (Figure 1a, c). The neurologist suggested idiopathic focal dystonia as a possible diagnosis with the normal findings of electromyography, nerve conduction velocity, and cervical spine magnetic resonance imaging (MRI). The serum uric acid level was elevated at $8.2 \mathrm{mg} / \mathrm{dL}$ and estimated glomerular filtration rate by Modification of Diet in Renal Disease was $67 \mathrm{~mL} /$ minute. His lipid panel was normal except for triglyceride (365 mg/dL). Plain radiography of his foot and ankle showed no abnormal findings. Ultrasonography revealed synovial hypertrophies at all the MCP, PIP, and distal interphalangeal (DIP) joints of his right hand with bony erosions and multiple hyper and hypoechogenic regions, representing tophi (Figure 2a). The second to fourth flexor digitorum tendons also showed diffuse thickening with hyperechogenicity along the sheaths (Figure $2 b$ ). MRI of the right hand revealed multiple areas of synovial and capsular enhancement at all the MCP, PIP, and DIP joints, and heterogenous signal intensities with enhancement around all flexor and extensor tendons (Figure 2c). Polarized microscopy of aspirate from a white deposit on his left ear showed many negativelybirefringent, needle-shaped crystals. Febuxostat (40 mg per day), nonsteroidal anti-inflammatory drugs and rehabilitation were started. Eight months later, the serum uric acid level decreased to $5.2 \mathrm{mg} / \mathrm{dL}$. The active $\mathrm{ROM}$ of the right second to fourth MCP joints improved from $5^{\circ}$ to $30^{\circ}$ of flexion, and that of the PIP joints from $30^{\circ}$ to $90^{\circ}$ (Figure $1 \mathrm{~b}, \mathrm{~d}$ ).

The causes of flexion contractures in this case are thought to be tophi between articular margins and swelling of flexor tendons. Gouty involvement of hands with tenosynovitis and tophi, even more as initial presentations, is unusual. ${ }^{2-4,6}$ With the changing pattern of gout and its expanding clinical spectrum, physicians should be aware that gout can occur even if the initial presentation is in the upper extremity. ${ }^{2,8}$ Because digital hand contractures without signs of acute inflammation can suggest gout, its evaluation should include a search for tophi or hyperuricemia. When there is unusual presentation of gout, it is necessary to rule out infection, neuropathy, another type of arthritis, and tumors. ${ }^{5,9}$ Most importantly, gout may be preferentially managed with medication, even if joint contractures are present.

\section{Declaration of conflicting interests}

The authors declared no conflicts of interest with respect to the authorship and/or publication of this article.

\section{Funding} Grant.

This work was supported by Inha University Research

\section{REFERENCES}

1. Ottaviani S, Bardin T, Richette P. Usefulness of ultrasonography for gout. Joint Bone Spine 2012;79:441-5. 
2. Arromdee E, Michet CJ, Crowson CS, O'Fallon WM, Gabriel SE. Epidemiology of gout: is the incidence rising? J Rheumatol 2002;29:2403-6.

3. Hernández-Cortés P, Caba M, Gómez-Sánchez R, Gómez-Morales M. Digital flexion contracture and severe carpal tunnel syndrome due to tophaceus infiltration of wrist flexor tendon: first manifestation of gout. Orthopedics 2011;34:797-9.

4. Weniger FG, Davison SP, Risin M, Salyapongse AN, Manders EK. Gouty flexor tenosynovitis of the digits: report of three cases. J Hand Surg Am 2003;28:669-72.

5. Yoshihara Y, Hayashi T, Matsushita S, Sugita H, Miki $\mathrm{H}$. Gouty flexor tenosynovitis of the hand mimicking atypical mycobacterial infection. Mod Rheumatol
2005; 15:427-31.

6. Sainsbury DC, Hidvegi N, Blair JW. Intra-tendinous gout in a repaired flexor digitorum profundus. J Hand Surg Eur Vol 2008;33:528-9.

7. Iwamoto T, Toki H, Ikari K, Yamanaka H, Momohara S. Multiple extensor tendon ruptures caused by tophaceous gout. Mod Rheumatol 2010;20:210-2.

8. Andracco R, Zampogna G, Parodi M, Paparo F, Cimmino MA. Dactylitis in gout. Ann Rheum Dis 2010;69:316.

9. Aslam N, Lo S, McNab I. Gouty flexor tenosynovitis mimicking infection: a case report emphasising the value of ultrasound in diagnosis. Acta Orthop Belg 2004;70:368-70. 